This item was submitted to Loughborough's Research Repository by the author.

Items in Figshare are protected by copyright, with all rights reserved, unless otherwise indicated.

\title{
Concussion in sport: Public, professional and critical sociologies
}

PLEASE CITE THE PUBLISHED VERSION

https://doi.org/10.1123/ssj.2017-0113

PUBLISHER

(c) Human Kinetics

VERSION

AM (Accepted Manuscript)

PUBLISHER STATEMENT

This work is made available according to the conditions of the Creative Commons Attribution-NonCommercialNoDerivatives 4.0 International (CC BY-NC-ND 4.0) licence. Full details of this licence are available at: https://creativecommons.org/licenses/by-nc-nd/4.0/

\section{LICENCE}

CC BY-NC-ND 4.0

\section{REPOSITORY RECORD}

Malcolm, Dominic. 2019. "Concussion in Sport: Public, Professional and Critical Sociologies". figshare. https://hdl.handle.net/2134/33825. 


\title{
Concussion in sport: public, professional and critical sociologies
}

\begin{abstract}
This article explores the emerging agenda in relation to concussion in sport to illustrate the threats and opportunities currently faced by the sociology of sport as an academic subdiscipline. The article begins by delineating aspects of the "crisis” in sociology, Burawoy's (2005) call for an enhanced public sociology as a (part) solution, and responses to these ideas within the sociology of sport. It then identifies how the engagement of sociologists in this terrain must be understood in relation to the recent medicalization of sports-related concussion, and illustrates the impact of this on sociologists of sport through an examination of recent social scientific scholarship in relation to concussion. It argues that a successful public sociology of sport should be predicated on the subdiscipline's distinctive contribution to the production of knowledge. To this end, the article concludes by reporting the findings of an empirical study of concussion in English professional football, to outline a framework for sport-related health research, and thus the basis on which a socially influential sociology of concussion in sport could develop.
\end{abstract}

\section{Introduction}

Sport-related concussion (SRC) has become an increasingly acute medical and social problem.

While the limitations of such quantitative assessments are discussed below, indicatively it is believed that each year there are 1.6-3.8 million SRCs in the US (Nathanson et al., 2016) and 2.1 million SRCs in youth football globally. Mainstream and social media report on SRC with increasing frequency and depth (Ahmed \& Hall, 2017; Sullivan et al., 2012), with concerns particularly focused on longer-term effects on cognitive functioning. For example, former NFL players have been found to be three times more likely than the general population to suffer a neurodegenerative disease (Partridge \& Hall, 2014, p. 2) and data has recently emerged to suggest that soccer players may develop similar forms of chronic traumatic encephalopathy (CTE) - defined as 'a degenerative brain disease linked to repeated head trauma and characterised by dementia-like symptoms, memory disturbances, and speech problems' (Partridge, 2014, p. 66) - through regular heading of the ball (Ling et al., 2017). Significantly 
however, medical literature (McCrory et al., 2017) and media reports (McGannon et al., 2013) fundamentally represent concussion as a condition about which relatively little is known.

The combination of medical limitations and high media profile makes SRC of particular interest because it encapsulates the potential challenges currently faced by, and the opportunities available to, sociology (of sport) as an academic (sub-)discipline. SRC is indicative of both the expanding imperative of health (Lupton, 1995) and the increasing prominence of medicine and health within sports science (Malcolm, 2014). It resonates with the "crisis" which has led sociologists of sport to the "bottom of the epistemological hierarchy" within kinesiology (Andrews, 2008, p. 48), and the discipline-wide "crisis" that has led to calls for a more public sociology (Burawoy, 2005). Consequently this article attempts to: provide a sociological critique of the development of what has been called a "concussion industry" (McNamee \& Partridge, 2013, p. 17); analyse social scientific responses to the SRC agenda; and draw upon an empirical study of concussion in English professional football to illustrate the basis on which a socially influential sociology of SRC could develop. The paper argues that while public sociology is a high stakes "game," the particular costs/benefits are magnified when sociologists engage with socially powerful professions like medicine. While good (or harm) can come from such engagements, given the broader context of "crisis," it is essential for sociologists of sport to engage with these developments strategically if the subdiscipline is to prosper in future. The paper argues that public engagement should be predicated on the rigorous and sociologically distinctive production of knowledge. In order to develop this argument we need initially to understand the contemporary state of sociology and calls to resolve the so-called crisis through recognition and valuation of sociology's broad division of labor and public sociology in particular. 


\section{The crisis in sociology (of sport)}

“Current crisis” arguments can be traced back around half a century (e.g. Gouldner, 1970), but contemporary iterations centrally relate to recent social developments and the place of sociology within them. Neoliberal higher education agendas have "turned intellectuals into soulless academics with restricted vision” (Hollands \& Stanley, 2009, 3.11) chasing research money, publications, and promotion. While a broader challenge to traditional views of the authority of "experts” impacts across academia (Furedi, 2004), sociologists in particular struggle to maintain methodological expertise as private and public institutions routinely deploy "our" staple research tools of interview and survey, and arguably to greater effect (Savage \& Burrows, 2007). Social fluidity is said to create an ontological problem for sociology challenging the very nature of the discipline as we move "beyond societies" (Hollands \& Stanley, 2009). The consequences of crisis have been: a) the loss of a coherent "core" to sociology; b) fragmentation of the discipline (especially into business schools, but more pertinently for present purposes, sports science); and c) the opening up of sociology to theories and intellectual practices from other disciplines which, in turn; d) ultimately undermines the sense that sociology offers a distinctive analysis of the social (Hollands \& Stanley 2009; Dunning \& Hughes, 2013).

The most notable response has been the call for more effective engagement and communication in an attempt to raise the public profile of sociology (Burawoy, 2005). The idea that sociology has multiple publics is by no means new, but Burawoy's specific contribution was to locate public sociology alongside its professional (knowledge produced by and for sociologists), policy (sociology applied for “clients”) and critical (self-reflexive of theories and methodologies) forms as part of a mutually interdependent but frequently antagonistic broader division of labor within the discipline, and to argue that both the need for, and barriers to, public sociology are greater than ever. 
The notion of public sociology must be understood in relation to concepts such as public intellectualism and social activism. The former defines an intellectual who writes for the general public but, pace Gramsci, an intellectual whose ideas are influential (Bairner, 2009). Against this, the public sociologist is "a public intellectual who applies sociological ideas and findings to social (broadly defined) issues about which sociology (also defined broadly) has something to say” (Gans, 1988, cited in Donnelly \& Atkinson 2015, p. 367). As Bairner (2009) points out there is a tendency to conflate both with social activism but while such attempts to improve the world may be underpinned by a disciplinary or intellectual perspective, the latter essentially entails claims for the power of sport - as opposed to sociologists of sport - to evoke change. Donnelly \& Atkinson (2015) presciently identify that public sociology inevitably entails paradigmatic contestation for authority, suggesting that the most important question for public and practical or professional sociologists is whose knowledge counts (and indeed why)?

Notions of social activism and public intellectualism/sociology are increasingly being addressed in the sociology of sport literature. Jarvie (2007, p. 422), for instance, produced an “advocacy” piece on the need for public intellectuals in sport, based on "the capacity to see above and beyond existing debates, to get off the tramlines of discussion.” McDonald (2002) provided autobiographical reflections on social research and activism, arguing the case for making a distinction between the use of research to secure political goals and, more radically, the politicized application of research. Bairner (2009, p. 115) similarly but "unashamedly" drew “on personal experiences” of his work reforming football in Northern Ireland, arguing that his sports knowledge (as both a sports fan and a sports academic) facilitated a cultural capital that was instrumental to his acceptance/legitimacy as a policy actor. Finally Cooky (2017: 13) has argued that recent sports activism and advocacy in the US over gender and racial inequalities suggests “an eager audience receptive to our work” which thus makes "a call for a public sociology particularly compelling.” 
Additionally Malcolm (2012) and Donnelly \& Atkinson (2015) have attempted summative assessments of existing activism and public sociologies of sport. Donnelly \& Atkinson's review of past engagements is relatively positive, identifying elements of success in three domains: a) use of systematic data (e.g. in relation to stacking and quotas; monitoring the impact of Title IX; providing overviews of media representations of minorities; and in quantifying the impact of sports injuries); b) challenging the view of sport as a universal panacea; and c) in relation to equity and social reproduction in sport. Malcolm (2012), conversely, provides a rather more negative evaluation of selected attempts to disseminate sociological ideas through popular writing and the interchange between academic and popular writers. Notwithstanding recognition of the impact of Sugden \& Tomlinson’s (e.g. 1998; 1999) corpus of work, Malcolm (2012) damningly concludes that,

While it might perhaps be rash to conclude that the denigration of the sociology of sport is an inevitable consequence of public work, it would certainly seem reasonable to suggest that such engagements are highly problematic and have, to date, done little to raise the status of the sociology of sport in public eyes.

Where these reviews concur is in their recognition of the increasing importance of public sociology (of sport). Donnelly \& Atkinson (2015. p. 376) argue that, "the necessity of doing critical theory and public sociology as praxis has never been more real.” They further note that there are some "hopeful signs" (Donnelly \& Atkinson 2015, p. 377) in the medical and health sciences in terms of the democratization of knowledge, through imperatives of open access, translational work and media dissemination. Malcolm (2012) moreover makes a number of recommendations for future public engagement which include the need to exhibit a greater collective disciplinary consciousness, publicize the subdiscipline's collective knowledge gains and extol the merits of fundamentally sociological explanations. 
It is against this backdrop that this article explores the role of sociologists of sport in relation to SRC. As an essentially embodied condition, SRC leads sociologists to engage with the medical and health sciences and thus, potentially, paradigmatic contestation with what McNamee \& Partridge (2013) refer to as the "concussion industry.” Viewed processually, however, these developments can be framed in terms of the medicalization of concussion.

\section{The medicalization of concussion}

The medicalization of social issues has been an enduring feature of the last century, both within and outside of sport. Sociologists have largely critiqued medicalization - the process whereby 'a problem is defined in medical terms, defined using medical language, understood through the adoption of a medical framework, or “treated” with a medical intervention' (Conrad 2007: 5) - on the basis of the legitimacy of this seemingly imperialistic project. Through an expanded realm of influence medicine comes to be a tool of social control, for instance, adjudicating on athletes' rights to participate in relation to drug use, gender or (dis-)ability, or the morality of 'natural' life-course events, such as becoming physically less active or gaining weight (Malcolm 2017). Medicine occupies a privileged position informing governments on which aspects of social life entail acceptable and unacceptable risks (e.g. boxing, smoking tobacco, consuming alcohol). It is in this context that we should understand the response of the medical community to growing concerns over SRC. In relation to concussion, medicalization is apparent in three distinct domains: research, policy and practice.

A central component of medical engagement with SRC has been the deployment of epidemiological surveys in attempts to establish the scale of the "problem.” Indicatively, Delaney et al. (2008) and Fraas et al. (2014) found that nearly half of footballers (soccer) and rugby (union) players experienced at least one concussion per year, while Partridge (2014) cites 
Australian studies which indicate that Australian (rules) Football League (AFL) and National Rugby League (NRL) teams are likely to experience between five and seven concussions per season. National Football League (NFL) statistics record a concussion once every 2.5 games (Casson et al., 2010). But a sociologically informed critique of epidemiological research recognizes that such data should not simply be read as an "objective” reflection of incidence, for the very act of undertaking such research fundamentally changes human understanding of the condition and contributes to its construction as a social issue (Petersen \& Lupton, 1996). Simply stated (new branches of) epidemiological research almost inevitably indicates an increase in recorded incidence. There are, of course, some notable exceptions where, for example, epidemiology has highlighted the social determinants of health and, most pertinently, the work conducted by the NFL's Mild Traumatic Brain Injury Committee, against which former NFL players filed a law suit claiming that evidence identifying a link between playing the game and both short- and long-term neurocognitive damage had been concealed (FainaruWada and Fainaru 2013; Hardes 2017). But more frequently, through the hierarchy imposed on such isolated risk variables, contemporary epidemiology tends to emphasize individual responsibility and diminish the role of social structural factors (i.e. that the rules of sport rather than subcultural norms 'cause' concussion). The essentially quantitative nature of the approach favors the measurement of certain outputs (i.e. the frequency of repeat concussions and the points in the game when they occur) and concomitantly overlooks the lived experience of health/illness (e.g. how does medical vs lay diagnosis of concussion change participants' understanding of, and sensitivity towards, future symptomatic experiences?). While imprecision is recognized by epidemiologists themselves, reflexivity towards the predictive power of this approach is frequently lost or obscured in state and media uses of epidemiological data (for instance studies of soccer players estimate that SRCs constitute between 2\% and 25\% of all injuries, a variation that suggests that existing techniques are not fit for purpose). Rather, 
"the very choice of what phenomena require measurement and surveillance is a product of sociocultural processes," including the interests of individual researchers and their employers, the relative ease of measurement and the politically driven research funding environment (Petersen \& Lupton, 1996, p. 36). Epidemiological studies therefore have a tendency to selfperpetuate the social centrality of medicine. Research generates incidence rates, which alters social concerns, justifies further epidemiological monitoring and ultimately provides empirical evidence for the efficacy of medically-based “solutions” (e.g. more accurate diagnosis).

In terms of SRC policy, a series of international conferences has been established from which four Agreement/Consensus statements have been published effecting regulatory changes across a range of sports. While not without their critics (e.g. Craton \& Leslie, 2014), the latest Concussion in Sport Guidelines (CISG) are seen to constitute the "gold standard" management protocol (McCrory et al., 2017). Currently they entail three primary recommendations for athletes to: undergo baseline cognitive and concussion symptom testing; be assessed using a standardized Sports Concussion Assessment Tool or SCAT (although a Concussion Recognition Tool is also produced for use by those without medical training); and be wholly asymptomatic throughout a six-phase return to play (RTP), lasting a minimum of six days and overseen by a medical practitioner.

Tellingly however McNamee et al. (2015, p. 198) argue that there is insufficient transparency in: a) the burden of proof and the level of agreement required for “consensus;” b) the conduct of proceedings; and c) the selection of panel members, and thus one "may reasonably ask whether the consensus is the outcome of predetermined selection rather than the conformity of scientific opinion.” While the most recent Consensus Statement explicitly sought to address some of these concerns by publishing a summary of methodology (Meeuwisse et al. 2017), the sponsorship of this process by sports governing bodies "could be seen as an attempt to steer the concussion agenda" and may ultimately result in the production 
of guidelines, “simply used to justify their own policies and practices” (McNamee et al., 2015, p. 194). There is, note, no sociologically informed input to these concussion statements and/or policy changes.

While sociologists are less well qualified to debate the bio-scientific evidence behind these policy recommendations, we are perhaps ideally placed to explore their consequences. Thus, in terms of practice, one manifest outcome of SRC policy change has been to consolidate medical control over both the physiological condition and related social issues. For instance, deployment of the SCAT is predicated on the necessity of medical attendance. Similarly Partridge (2014) notes that AFL and NRL regulations require players suspected of sustaining a concussion to be assessed by a first aider yet also that players "need an urgent medical assessment by a medical practitioner" because "the management of head injury is difficult for non-medical personnel” (Partridge, 2014, pp. 67, 68). Most fundamentally, however, the primacy of medicine is established by the continued provision in the CISG of all RTP decisions remaining "largely in the realm of clinical judgment on an individual basis" (cited in McNamee et al., 2015, p. 192).

Thus, in recent years concussion has increasingly been brought into the provenance of medicine. It is testament to the social power of medicine that this jurisdictional expansion has occurred for a condition which in many respects does not require esoteric skills or specialist knowledge. The most frequently cited symptoms of concussion - memory loss, dizziness, loss of consciousness - are not hard to detect, most resolve spontaneously and few receive/require no medical intervention, yet ironically the condition is now claimed to be, "among the most complex injuries in sports medicine to diagnose, assess and manage” (McCrory et al., 2017, p. 2). As this article demonstrates, if concussion management is difficult, it is so partly because clinical autonomy is continually questioned in the sports milieu. But for present purposes it is important to note that because SRC is subject to elements of medical imperialism, if and when 
sociologists of sport enter the public domain of SRC, their actions and advocacy inevitably force comparison with that of the medical profession.

\section{Social scientific responses to the SRC agenda}

In contrast to medically-driven SRC developments, the work of social scientists (and ethicists), has been relatively tentative. Sports psychologists, in demonstrating the long-term psychological impacts such as anxiety, depression, social withdrawal, loss of identity and suicidal ideation, have been critical of the dominance of medicine's tendency to reduce neurocognitive outcomes through quantitative methodologies (Caron et al., 2013). Media analyses of the representation of SRC have focused on the portrayal of the balance between health precaution and a (masculine) culture of risk in sport (McGannon et al., 2013).

The literature on the ethics of concussion is more developed. McNamee and colleagues have, for instance, explored the ethical implications of concussion treatment including problems relating to paternalistic intervention, conflicting and competing interests and issues related to confidentiality (McNamee et al., 2015a). They consider, for instance, the ethical rationale for the more conservative treatment of children despite the weakness of supporting evidence. They further explore the developing body of protocols identifying 'numerous problems' in the implementation of best practice protocols across sports diverse domains (McNamee et al., 2016). Most recently Lopez Frias and McNamee (2017) have considered the ethical basis for reforming or eliminating sports with high risks of brain injuries and concluded that these 'are not well founded' (p. 264).

To date sociologists of sport have provided just two studies of the lived experience of SRC. Malcolm (2009) initially drew on figurational sociology and concepts of medical 
uncertainty to explain how and why this sporting community sometimes circumvented, and sometimes openly rejected, relatively precautionary SRC policy initiatives. He further concluded that the unintended consequences of rules designed to protect players' health could lead clinicians to replace textbook diagnostic criteria with more subjective understandings of concussion, "that they know will be acceptable to others" (Malcolm, 2009, p. 201). Subsequently Liston et al. (2016) reported on a qualitative, interview-based, study with adult players in non-elite club rugby union to explore the frames of reference within which sports participants perceive, give meaning to and manage concussion. This illustrated how attitudes towards head injuries are not simply resistant to medical intervention, but irreverent, encouraging risky behaviours in relation to concussion. This study of Irish amateur rugby players showed that individuals (for generally they had no dedicated healthcare support) managed concussion by downplaying, ignoring, denying the significance of, or concealing the symptoms and "playing on.” Post-injury consequences such as sleep disturbance, irritability and mood swings were hidden from others. There was, moreover, testimony to the effect of exhibiting a preference for receiving a concussion over such things as muscular injuries. The rationale presented was that the former frequently entailed a more limited impact on a person's ability to play rugby. Experiences of cognitive impairment due to concussion were equivocal, for instance described as simply 'reverting' the individual to a 'primal state'. Severity of injury, conversely, was assessed by these players as being directly related to the length of time one was unable to play sport, and excluded criteria such as longer term neurocognitive decline. Such a 'head strong' attitude, was derived, 'from within the subculture of rugby, that is, originating in the level of commitment made by players to each other and to the game' (Liston et al., 2016, p. 9). These pieces demonstrate that social factors are not only significant but potentially also predominant in the management of SRC. This statement encapsulates the 
unique contribution sociology can make to the understanding of SRC which we expand upon in the next section.

Additional to this "professional sociology” (Burawoy, 2005) of SRC, have been social scientists who have engaged in a form of social activism challenging debates around SRC. These debates have received formal political recognition in the UK with concussion explicitly mentioned a number of times in Grey-Thompson's (2017) recent Duty of Care in Sport: Independent Report to Government. Predominantly however social scientists have been active in critiquing the responses of sports governing bodies to calls to alter the rules of certain sports (e.g. the banning of heading in soccer or tackling in rugby). World Rugby was persuaded to retract 'erroneous and misleading’ injury statistics (Piggin \& Pollock, 2017), and similarly ‘misleading official claims’ published in England Rugby’s 'Rugby Safe' booklet have been critiqued (Piggin, 2017). While both laudable in their aims and significant in their impact, a notable characteristic is the relatively marginal position of social scientific and/or sociological knowledge within these critiques. While the 'de-bunking' of myths has long been part of the remit of sociologists, it is not exclusive to the discipline. Pace McDonald (2002) and Malcolm (2012), these works did use social research for political ends but do not publicize sociological knowledge gains. Indeed, the central aspects of "fact" that are being disputed (e.g. interpretations of the incidence of risks) are derived from epidemiological work which, and as noted above, requires a more fundamental critical sociological engagement.

Second these works ultimately evidence the increasingly blurred disciplinary boundaries, for the perspective adopted was essentially ethical rather than sociological. They are, therefore, indicative of the fragmentation of sociology, and the deference towards nonsociological paradigms that has been depicted as part of the sociological crisis and, in particular, is evident in the sociology of sport. Pace Donnelly \& Atkinson (2015), these debates 
give the appearance that it is epidemiological and perhaps ethical knowledge that counts, and therefore embodies the crisis of contemporary sociology.

Third, there is a sense in which these interventions remain divorced from their organic public (Cooky, 2017). Not only are academics yet to actively engage with the significant number of high profile doctors and former players who are equally critical of the status quo, as Gibson (2018) points out 'the voices of those most affected by a ban, namely children and young people, are missing from the literature’. As Bairner (2009, p. 115) notes, “only through engagement with organic intellectuals who exercise authority within the subcultures of sport can critical sociologists hope to influence sporting practices.” Amongst our publics - receptive to the democratization of knowledge that has eroded the authority of academic elites in general, and sociologists in particular - experience and/or cultural capital counts. We may take ethical stands, but we would be sociologically naive to assume that the broader public will see such positions as compelling, privileged or expert. Rather, for sociologists of sport to be socially influential, we must harness the sociological perspective and demonstrate our relative and distinctive intellectual contribution. To this end, sociologists are potentially well-equipped to relate the experiences of marginalized and disadvantaged groups, use this knowledge to challenge hegemonic perspectives (Cooky, 2017), and further to undertake a more fundamental critical analysis of the social construction of that hegemonic knowledge/status. This is never more apparent than in relation to the sometimes distant and de-humanized (medical) paradigm which currently dominates the SRC agenda.

\section{Towards a (public) sociology of SRC: the role of critical and professional sociologies}

How then can sociologists of sport engage with an activist agenda, and what sociological insights should form the basis of a SRC public sociology? Pace Burawoy (2005), a successful 
public sociology (of sport) requires a degree of balance between political activity and knowledge production, an interdependence between public, professional and critical sociologies which may, in turn, contribute to policy sociology. While the legacy of such debates remain in the various labelling of sport sociology/sociology of sport, medical sociology/sociology of medicine has been dealing with such issues for longer and perhaps more explicitly due to that subdiscipline's close association with a more powerful social institution. Consequently the importance of professional sociological knowledge in this context can be illustrated through Timmermans’ (2013) critical sociological framework for researchers who, he suggests, do not simply want to support or bolster the work of medicine, but reflect upon and evaluate the concept and social functioning of health per se. Timmermans outlines seven "warrants," five of which - exploring the social construction of medical beliefs; reframing dominant perspectives; charting winners and losers; identifying unfulfilled promises; and revealing the role of social relations - are explored here in relation to SRC.

The illustration of this framework draws on interview data from a study of doctors and physiotherapists working in professional football in England (Malcolm et al., 2017), to demonstrate the potential for sociologists as qualitative (health) researchers to speak to the SRC agenda and provide insights that it would be difficult or impossible for other disciplines to provide. The data were collected as part of a broader project on the appointment procedures and working practices of sports medicine clinicians working in the English Premiership and Football Leagues, the sample consisted of doctors $(n=8)$ and physiotherapists $(n=14)$ appointed as "lead" clinician in their respective areas of practice at one of these 92 clubs, and the project entailed both a questionnaire and interview (though only data from the latter is reported here). Even within this single project we can begin to illustrate the type and scope of research that could form the basis of distinctly public sociological work on SRC. 


\section{Exploring the social construction of medical beliefs}

Interviews with clinicians working in English professional football illustrated the extent to which knowledge about concussion relied less on what was stated in the medical texts, sport regulations and concussion awareness materials, and more directly on the lived experience. This was most evident in relation to the criteria clinicians used to diagnose concussion. As with previous research (Malcolm, 2009), interviewees focused on loss of consciousness (LOC) as the necessary, but non-sufficient, criterion by which to diagnose concussion, despite the widespread belief that LOC is present in just $10 \%$ of SRCs. A League One physiotherapist noted, "I think loss of consciousness is [the definitive diagnosis], I think that would dictate how much the severity of the initial trauma was.” Similarly a Premiership doctor said "unconsciousness is the key to it [diagnosis], yes.” But interviewees further elaborated that, in addition to LOC, they assessed the severity of head injuries primarily in terms of the players' broader functioning, such as a player's movement (League one physiotherapist), vision (Premiership physiotherapist) and/or cognitive coherence. A League One physiotherapist provided the following example of an incident which did not result in a diagnosis of concussion:

The player went down like he'd been knocked unconscious so I'm there within seconds.

I'd never known a player to be knocked out by the ball to be perfectly honest. And he was, after a minute or so, he was fine, he was talking to me straight away ... so he'd not even opened his eyes by that time but he’s answering the questions.

Because what occurs in the practice setting is often a far cry from the confines of conditions as specified in medical literature, a public sociology of sport has the unique capacity to demonstrate the processes by which medical beliefs are not necessarily based on scientific evidence, but emerge in a social context. 


\section{Reframing dominant perspectives}

Extending the exposition of the social construction of SRC beliefs, sociology can expose the fallacy of positioning medicine as providing a comprehensive solution to this "social problem." In contrast to the reliance SRC policy places on medical personnel, and the implicit assumption of utility, interviewees talked about their own limitations. Physiotherapists described diagnosis of concussion as "very difficult” (Championship) and "hard to sort of diagnose with your eyes” (League One). A Championship doctor similarly argued that, "the most difficult [injuries] I think are head injuries...you're not quite sure, is the player really concussed or is he a bit stupid.” Contra to the medicalization of SRC policy, a(nother) Championship doctor explicitly deferred to his non-medically qualified colleagues in saying, “The physios ... are very capable, and probably more experienced than a lot of doctors at assessing.”

As part of the representational image of the profession, medical journals are unlikely to foster work which exposes the limitations of the problem-solving function on which the profession's social value rests. The role of a public sociology of SRC is, therefore, to illustrate the disparity between the scientific and practice communities' portrayal of efficacy and thus challenge existing assumptions about the source of resolution for this social problem.

\section{Charting the winners and losers of health interventions}

A further distinct sociological contribution is to highlight variations in the deployment of SRC management protocols. To this end interviewees revealed that, contrary to the national governing body's recommendation, the use of baseline cognitive testing was particularly rare. This was primarily attributed to economic concerns. As a League two physiotherapist alluded, 
"at the end of the day the chairman is the chairman ... is he going to pay for that? Probably not you know.” Yet even free-to-use interventions were variously employed. As a League Two physiotherapist said, "we go off the SCAT3 results and intuition really” (emphasis added). Similarly evidence of the use of the RTP protocol was varied, and interviewees talked about players who had returned in 5 days or who had taken seven days, but had only received medical supervision on "3 or 4 days" (League One physiotherapist) during the six-phased RTP. In addition to these procedural shortcomings, some interviewees talked about the possibilities of deliberately circumventing treatment protocols. A Championship physiotherapist argued that, “you can look at those guidelines and you can fudge it ... it's not an obvious thing that you can’t play.” The most explicit avoidance strategy was reported by a second Championship physiotherapist who described their response to players that came to them reporting concussion symptoms: “I’m always like, “do you want to have this conversation? As soon as you tell me you're dizzy ..."

The SRC literature that has hitherto been produced by medical researchers has highlighted athletes' limited knowledge of concussion (Williams et al., 2016), and their attempts to avoid diagnosis. Because of their own professional commitments, they are unlikely to detail clinicians' limitations and/or non-compliance to concussion management protocols which are, paradoxically, largely driven by the medicalization of concussion. A public sociology of SRC is therefore needed to illustrate how certain people, in certain contexts, benefit from medical provision while others may experience medical mismanagement.

\section{Identifying the unfulfilled promises of medicine}

Diagnosis has traditionally been a central pillar of medical authority (Jutel, 2009), yet clinicians consistently displayed heightened degrees of diagnostic uncertainty in relation to SRC. For 
instance, a Premiership physiotherapist specifically critiqued the contextually specific meaningfulness of medical definitions of concussion: "if you're heading the ball is there a slight trauma to the brain? Then therefore is that concussion? ... Is that a definition of it, or this, that and the other?" Diagnostic variability meant that assessments of the incidence of concussion varied widely. Most interviewees described concussion as rare in football. For instance, a Premier league physiotherapist stated that s/he had probably only seen two concussions in 15 years of working in the sport. Conversely, the highest estimate of incidence came from physiotherapists in lower league clubs, where some argued that, "the majority of players will come off with a headache anyway ... I'd probably say every third game you probably get a head injury noteworthy of having a look at” (League One physiotherapist, emphasis added). Contra to the CISG, clinicians echoed the media discourse (Ahmed \& Hall, 2017) of attempting to provide gradations of SRC. For instance, a Championship physiotherapist, when asked how frequently s/he dealt with concussion-related issues, replied:

I’m struggling to think. We've had some head injuries this year. I can think of two but the player wasn’t concussed on either occasion. What level of concussion are we talking about?

Similarly, a Premier league physiotherapist stated that each season the first team would normally experience "half a dozen perhaps... [but] if you include the minor ones up to a dozen.” In exercising individual clinical judgement (as advocated in the CISG), these clinicians ultimately acted contrary to the sport's regulations in drawing their own diagnoses of "major" and "minor" concussions. They both experienced and provided evidence of diagnostic uncertainty and thus the unfulfilled promise of medicine.

A number of interviewees actively identified the failure of medicine to supply solutions for SRC. For instance, respondents cited the changing concussion guidelines as evidence of 
uncertainty in the sports medicine community: "they used to say he was out for 3 weeks ... and now they're saying 'we're not saying 3 weeks, we're saying he might be alright, but then he might be alright in 5 weeks'” (League two physiotherapist). A Premiership doctor argued that concussion management guidelines,

on the face of it seem very clear, but in reality it's not like that at all, by the time you get to a player. I've got to a player who I thought was clearly unconscious and then he's just opened his eyes and said "I'm alright doc."

Others cited the lack of evidence for both second impact syndrome (where subsequent head injuries become increasingly regular and/or severe) and the necessity of a phased RTP as indicative of "lots of uncertainty" (League one doctor). Due to the uncertainty clinicians experienced, some recalled sending players with head injuries to Emergency Medicine (EM) clinics for assessment. Universally, however, this failed to resolve their concerns. A League Two doctor stated that s/he would unlikely do so again because "they’re probably just going to look them over and say they'll be fine and send them home.” A Championship doctor recalled how a player suspected of being concussed at an away game was sent to EM only for them to "put him on a bus to send him home. You know, 6 hours up the motorway and you never know.”

A public sociology of SRC is thus uniquely placed to identify the disparity between the public and paradigmatic promises of medicine and the private problems of practice, thereby contributing towards their resolution.

\section{Revealing how social relations mediate the impact of medical and health interventions}


Finally, and perhaps most fundamentally, a public sociology of SRC is required to illustrate the role of social relations in medical work. In this respect, interviewees reported instances where their clinical autonomy came under pressure from either or both of their two main “clients” - players and coaches/management - and how this had a tangible effect on practice.

Clinicians described examples of diagnosis avoidance and dispute, and treatment rejection. Many thought that players had, and would, avoid diagnosis by hiding symptoms. A League One physiotherapist noted, “if someone had banged their head ... they'd probably get on with it ... you wouldn't see it unless they had real issues or problems with it.” Even when head injuries came to the attention of clinicians, players might insist on being symptom-free (League Two physiotherapist) or become "very aggressive, wanting to stay on the pitch. It took a lot of convincing that he wasn’t right” (Championship physiotherapist). Problems of player management were further evident in the implementation of the RTP protocol. A Championship doctor noted that, "you offer them [players] a seven-day ruling for them to stay away, and sometimes they get a little bit ... they don’t want to go by that.” Another Championship doctor described a case when a player disputed a prognosis and "finished up with him [the player] signing a declaration that he accepted what I said ... [and that the club] had not put any pressure on him to play.”

Clinicians also spoke about the pressures exerted by club managers. For instance it was claimed that “a lot would attempt to interfere” (Championship doctor) in SRC decision-making. A Championship physiotherapist described the type of pressure experienced during games:

I’ve had managers tell me “make sure he stays on the pitch; I haven’t got anyone else to play in that position.” Well it's not the care of the player that's important to them, it's the fact he hasn't got anybody to replace him. He’s got a football match to win ... some of 
them are better at understanding that [the physiotherapist's duty of care] but in general, yeah, they are under loads of pressure.

Similarly a League Two physiotherapist argued that where players' symptoms resolved relatively quickly, a delayed RTP could be "hard to justify.” A Premiership physiotherapist said that "The next day he'll [the manager] come across and say you've got to have him for Saturday, and things like that.”

The reality of SRC (and many other conditions) is that social relations exert a huge influence on medical management. Sociology (of sport) has a unique but also socially valuable role to play in exposing those social relations and, in so doing, both enhancing the medical management of SRC and contributing to the wellbeing of human populations.

\section{Conclusion}

As Burawoy (2005, p. 6) argues, "the aspiration for public sociology is stronger and its realization ever more difficult.” What is true for the parent discipline is equally if not more imperative for sociologists of sport. If we, as sociologists of sport, believe we have a distinct and valuable contribution to make to enhancing the human condition, it logically follows that we not only have a professional and moral obligation to conduct public sociology, but to do so in a way which augments the social status of the (sub-)discipline. Actions which may be strategically appropriate for a discipline such as public health/epidemiology which sit prominently in the epistemological hierarchy, may not help convince a more broadly sceptical public of the value and legitimacy of the sociology of sport.

Consequently, we must be cognisant of the potentially detrimental impact such public engagements may entail, and conduct due diligence to militate against such harms. This article 
identifies recommendations for public engagement which enhances our field (Malcolm, 2012), strategies for maximizing our impact through engaging with strategic partners such as organic intellectuals (Bairner, 2009), and empirical themes (such as evidencing inequality of provision or the impact of social relations on scientific practice) which provide clear opportunities for sociological contributions. As Cooky notes (2017, p. 26), “not everyone can or may wish to engage in public sociology," but given the broader academic and disciplinary "crisis" it is important to learn from our own and others' experiences in order that we succeed in raising the social status of the field. Part of a coherent core of knowledge for the sociology of sport should include a reflexive understanding of relevant examples of public engagement.

Specifically in relation to concussion, sociologists of sport should reach out to the players' associations which are charged with the responsibility to protect athlete wellbeing, and the brain injury charities which are currently petitioning sports governing bodies to take concussion more seriously. Sociologists of sport should also embrace the growing community of high profile sportspeople who are speaking out on this issue. Here a convergence of interests is clearly evident. But additionally, through access to what Burawoy (2005) identifies as one of our primary 'publics' (i.e. students), sociologists of sport are particularly well positioned to inform, educate and subsequently to shape grassroots practice. There are many students on our campuses that have experienced first-hand the limited ability of medicine to effectively manage or even resolve their concussion-related problems. While frequently steeped in the sport ethic, the unpredictability of concussion sequelae and the elemental concerns of apparent brain injury foster a more critical questioning the ideologies informing sporting cultures. Participation in future CISG meetings and consensus statements would be evidence of impact, but the ultimate goal of a public sociology of sports injuries per se would be to empower players to avoid health compromising behaviours and foster an environment in which they had the support of coaches, managers and their peers in so doing. But concussion is just one example of the multiple health 
risks encountered in (elite) sport and one of the strengths of the sociological perspective is that it enables the researcher to take a more holistic and comprehensive perspective while retaining a critical distance from the more emotive aspects of this 'concussion crisis'.

Fortunately for sociologists of sport there appear to be multiple possibilities to conduct contemporary empirical research which directly highlights aspects of the human condition, enhances lives and looks to constrain the sometimes unsubstantiated and unwarranted reach of the powerful groups that currently dominate public intellectual agendas. SRC is just one, albeit obvious, example. In light of this the degree to which sociologists of sport have talked about this issue rather than published research on its social manifestations is really quite disappointing. Dunning (2004, p. 18) may then be correct in suggesting that placing "the need for action above, rather than together with, the need for understanding” is one of the major threats to the "balance" of the subdiscipline. Public, professional, policy and critical sociologies need to be mutually interacting to address the current crisis within the discipline.

\section{References}

Ahmed, O. \& Hall, E. (2017) "It was only a mild concussion:” Exploring the description of sports concussion in online news articles. Physical Therapy in Sport, 23, 7-13.

Anderson, E. \& Kian, E. (2012) Examining media contestation of masculinity and head trauma in the National Football League. Men and Masculinities, 15(2), 152-173.

Andrews, D. (2008) Kinesiology's inconvenient truth and the physical cultural studies imperative. Quest, 60(1), 45-62.

Bairner, A. (2009) Sport, intellectuals and public sociology: Obstacles and opportunities. International Review for the Sociology of Sport, 44(2-3), 115-130. 
Burawoy, M. (2005) For public sociology. American Sociological Review, 70, 4-28.

Caron, J., Bloom, G., Johnston, K. \& Sabiston, C. (2013) Effects of multiple concussions on retired National Hockey League players. Journal of Sport and Exercise Psychology, 35, 168-179.

Casson, I., Viano, D., Powell, J. \& Pellman, E. (2010) Twelve years of National Football League concussion data. Sport Health, 2(6), 471-483.

Cooky, C. (2017) “We cannot stand idly by:” A necessary call for a public sociology of sport, Sociology of Sport Journal, DOI: http://dx.doi.org/10.1123/ssj.2016-0156.

Conrad, P. (2007) The Medicalization of Society: On the Transformation of Human Conditions into Treatable Disorders. London: Johns Hopkins University Press.

Craton, N. \& Leslie, O. (2014) Time to re-think the Zurich guidelines? A critique on the consensus statement on concussion in sport, held in Zurich, November 2012. Clinical Journal of Sports Medicine, 24(2), 93-95.

Delaney, J., Al-Kahmiri, A., Drummond, R. \& Correa, J. (2008) The effect of protective headgear on head injuries and concussions in adolescent football (soccer) players. British Journal of Sports Medicine, 42, 110-115.

Donnelly, P. \& Atkinson, M. (2015) Where history meets biography: Towards a public sociology of sport. In: R. Field (Ed.) Playing for Change: The continuing struggle for sport and recreation (pp.361-389). Toronto: University of Toronto Press.

Dunning, E. \& Hughes, J. (2013) Norbert Elias, Sociology and the Human Crisis: Interdependence, Power, Process. Cambridge: Polity.

Fainaru-Wada, M. \& Fainaru, S. (2013) League of Denial. 
Fraas, M., Coughlan, G., Hart, E. \& McCarthy, C. (2014) Concussion history and reporting rates in elite Irish rugby union players. Physical Therapy in Sport, 15, 136-142.

Furedi, F. (2004) Where have all the intellectuals gone? Confronting 21st century philistinism. London: Continuum.

Gibson, K. (2018) Banning the tackle in school rugby: Let's put it into context. https://blogs.bmj.com/bjsm/2018/01/30/banning-tackle-school-rugby-lets-put-context/. Accessed 2 February 2018.

Gouldner, A. (1970) The Coming Crisis of Western Sociology. London: Heinneman.

Grey-Thompson, T. (2017) Duty of Care in Sport: Independent Report to Government. https://www.gov.uk/government/uploads/system/uploads/attachment_data/file/610130/ Duty_of_Care_Review_-_April_2017_2.pdf. Accessed 2 February 2018.

Hardes, J. (2017) Governing sporting brains: Concussion, neuroscience, and the biopolitical regulation of sport. Sport, Ethics and Philosophy, 11(3), 281-293.

Hollands, R. \& Stanley, L. (2009) Rethinking “current crisis” arguments: Gouldner and the legacy of critical sociology. Sociological Research Online, 14(1)1.

Jarvie, G. (2007) Sport, social change and the public intellectual. International Review for the Sociology of Sport, 42(4), 411-424.

Jutel, A. (2009) Sociology of diagnosis: A preliminary review. Sociology of Health \& Illness, 38(2), 387-399.

Ling, H., Morris, H., Neal, J., Lees, A., Hardy, J., Holton, J., Revesz, T., Williams, D. (2017) Mixed pathologies including chronic traumatic encephalopathy account for dementia in retired association football (soccer) players, Acta Neuropathologica, 133, 1-16. 
Liston, K., McDowell, M., Malcolm, D., Scott, A. \& Waddington, I. (2016) On Being “Head Strong:” The Pain Zone and Concussion in Non-Elite Rugby Union. International Review for the Sociology of Sport, DOI: 10.1177/1012690216679966

Lopez Frias, J.F. \& McNamee, M. (2017) Ethics, Brain Injuries, and Sports: Prohibition, Reform, and Prudence. Sport, Ethics and Philosophy, 11(3), 264-280.

Lupton, D. (1995) The Imperative of Health. Public Health and the Regulated Body. London: Sage.

McDonald, I. (2002) Critical social research and political intervention: Moralistic versus radical approaches. In: J. Sugden \& A. Tomlinson (Eds) Power Games: A Critical Sociology of Sport. London: Routledge.

Malcolm, D. (2009) Medical uncertainty and clinician-athlete relations: The management of concussion injuries in rugby union. Sociology of Sport Journal, 26(2), 191-210.

Malcolm, D. (2012) Sport and Sociology. London: Routledge.

Malcolm, D. (2014) Sport, medicine and health: A research agenda for social scientists. AsiaPacific Journal of Sport and Social Science, 3(1), 51-63.

Malcolm, D. (2017) Sport, Medicine and Health: The Medicalization of Sport? London: Routledge.

Malcolm, D., Scott, A. \& Waddington, I. (2017) The provision of medical care in English professional football: an update. Journal of Science and Medicine in Sport, DOI: http://dx.doi.org/10.1016/j.jsams.2017.05.004. 
McCrory, P., Meeuwisse, W., Dvorak, J., et al (2017) Consensus statement on concussion in sport - the 5th International Conference on Concussion in Sport held in Berlin, October 2016. British Journal of Sports Medicine, doi:10.1136/bjsports-2017-097699.

McGannon, K., Cunningham, S. \& Schinke, R. (2013) Understanding concussion in sociocultural context: A media analysis of a National Hockey League star’s concussion. Psychology of Sport and Exercise, 14, 891-899.

McNamee, M. \& Partridge, B. (2013) Concussion in sports medicine ethics: policy, epistemic and ethical problems. Sports Medicine \& Ethics, 13(10), 15-17.

McNamee, M., Partridge, B. \& Anderson, L. (2015a) Concussion in sport: Conceptual and ethical issues. Kinesiology Review, 4, 190-202.

McNamee, M., Partridge, B. \& Anderson, L. (2016) Concussion ethics and sports medicine. Clinics in Sports Medicine, 35(2), 257-67.

Meeuwisse, W.H., Schnieder, K.J., Dvorak, J., Omu, O., Finch, C., hayden, K.A. \& McCrory, P. (2017) The Berlin 2016 process: A summary of methodology for the $5^{\text {th }}$ International Consensus Conference on Concussion in Sport. British Journal of Sports Medicine, doi:10.1136/bjsports-2017-097569.

Nathanson, J.T., Connolly. J.G., Yuk, F., Gometz, A., Rasouli, J., Lovell, M. (2016) Concussion incidence in professional football: position-specific analysis with use of a novel metric. Orthopeadic Journal of Sports Medicine, 4, 1-6.

Partridge, B. (2014) Dazed and confused: sports medicine, conflicts of interest, and concussion management. Bioethical Inquiry, 11, 65-74. 
Partridge, B. \& Hall, W. (2014) Repeated head injuries in Australia’s collision sports highlight ethical and evidential gaps in concussion management policies. Neuroethics,8(1), 39-45.

Petersen, A. \& Lupton, D. (1996) The New Public Health: Discourses, Knowledges, Strategies. London: Sage.

Piggin, J. (2017) Rugby, risk and rhetoric: The trivialisation of injury data must end. New Zealnad Journal of Sports Medicine, 44(1)

Piggin, J. \& Pollock, A. (2017) World Rugby’s erroneous and misleading representation of Australian sports’ injury statistics. British Journal of Sports Medicine, 51, 1108.

Savage, M. \& Burrows, R. (2007) The coming crisis of empirical sociology. Sociology, 41(5), 885-899.

Sugden, J. \& Tomlinson, A. (1998) FIFA and the Contest for World Football: Who Rules the Peoples’ Game? Cambridge: Polity Press.

Sugden, J. \& Tomlinson, A. (1999) Great Balls of Fire: How Big Money is Hijacking World Football. Edinburgh: Mainstream.

Sullivan, S., Schneiders, A., Cheang, C., Kitto, E., Lee, H., Redhead, J., Ward, S., Ahmed, O. \& McCrory, P. (2012) “What’s happening?” A contend analysis of concussion-related traffic on Twitter. British Journal of Sports Medicine, 46, 258-263.

Timmermans, S. (2013) Seven warrants for qualitative health sociology. Social Science \& Medicine, 77, 1-8. 
Williams, J.M., Langdon, J.L., McMillan, J.L., Buckley, T.A. (2016) English professional football players' concussion knowledge and attitude. Journal of Sport Health Science, 6, 197-204. 